\title{
Skeletal Muscle Pathophysiology: The Emerging Role of Spermine Oxidase and Spermidine
}

\author{
Manuela Cervelli ${ }^{1, *(1)}$, Alessia Leonetti ${ }^{1}\left(\mathbb{D}\right.$, Guglielmo Duranti $^{2}$, Stefania Sabatini ${ }^{2}$, \\ Roberta Ceci ${ }^{2}$ and Paolo Mariottini ${ }^{1}$ \\ 1 Department of Science, Università degli Studi di Roma “Roma Tre", 00146 Rome, Italy; \\ alessia.leonetti@uniroma3.it (A.L.); paolo.mariottini@uniroma3.it (P.M.) \\ 2 Department of of Movement Human and Health Sciences, Unit of Biology, Genetics and Biochemistry, \\ Università degli Studi di Roma "Foro Italico", Piazza Lauro De Bosis 15, 00135 Rome, Italy; \\ guglielmo.duranti@uniroma4.it (G.D.); stefania.sabatini@uniroma4.it (S.S.); roberta.ceci@uniroma4.it (R.C.) \\ * Correspondence: manuela.cervelli@uniroma3.it
}

Received: 30 November 2017; Accepted: 9 February 2018; Published: 14 February 2018

\begin{abstract}
Skeletal muscle comprises approximately $40 \%$ of the total body mass. Preserving muscle health and function is essential for the entire body in order to counteract chronic diseases such as type II diabetes, cardiovascular diseases, and cancer. Prolonged physical inactivity, particularly among the elderly, causes muscle atrophy, a pathological state with adverse outcomes such as poor quality of life, physical disability, and high mortality. In murine skeletal muscle $\mathrm{C} 2 \mathrm{C} 12$ cells, increased expression of the spermine oxidase (SMOX) enzyme has been found during cell differentiation. Notably, SMOX overexpression increases muscle fiber size, while SMOX reduction was enough to induce muscle atrophy in multiple murine models. Of note, the SMOX reaction product spermidine appears to be involved in skeletal muscle atrophy/hypertrophy. It is effective in reactivating autophagy, ameliorating the myopathic defects of collagen VI-null mice. Moreover, spermidine treatment, if combined with exercise, can affect D-gal-induced aging-related skeletal muscle atrophy. This review hypothesizes a role for SMOX during skeletal muscle differentiation and outlines its role and that of spermidine in muscle atrophy. The identification of new molecular pathways involved in the maintenance of skeletal muscle health could be beneficial in developing novel therapeutic lead compounds to treat muscle atrophy.
\end{abstract}

Keywords: aging; atrophy; autophagy; oxidative stress; polyamines; skeletal muscle; spermidine; spermine oxidase; transgenic mouse

\section{Introduction}

Skeletal muscle is the largest tissue of the human body and represents $40-50 \%$ of body weight, varying according to physiological and pathological conditions [1]. Skeletal muscle atrophy is a frequent and disabling condition. It involves different molecular mechanisms that occur during pathogenesis, hence knowledge of the cellular signal pathways that mediate muscle atrophy is still limited [2].

Polyamines (PAs) are essential for normal cell growth, proliferation, and differentiation, and the tissue levels of individual PAs are maintained and buffered via complex regulatory mechanisms $[3,4]$. The functional roles of the natural PAs, putrescine (Put), spermidine (Spd), and spermine (Spm), are under active investigation in broad research areas, from neuroscience to cancer and biochemistry [5-9]. Two key enzymes, ornithine decarboxylase and S-adenosylmethionine decarboxylase, control PA biosynthesis. PA catabolism is finely regulated by the enzymes $N^{1}$-acetyltransferase, polyamine oxidase, and spermine oxidase (SMOX) (Figure 1). 


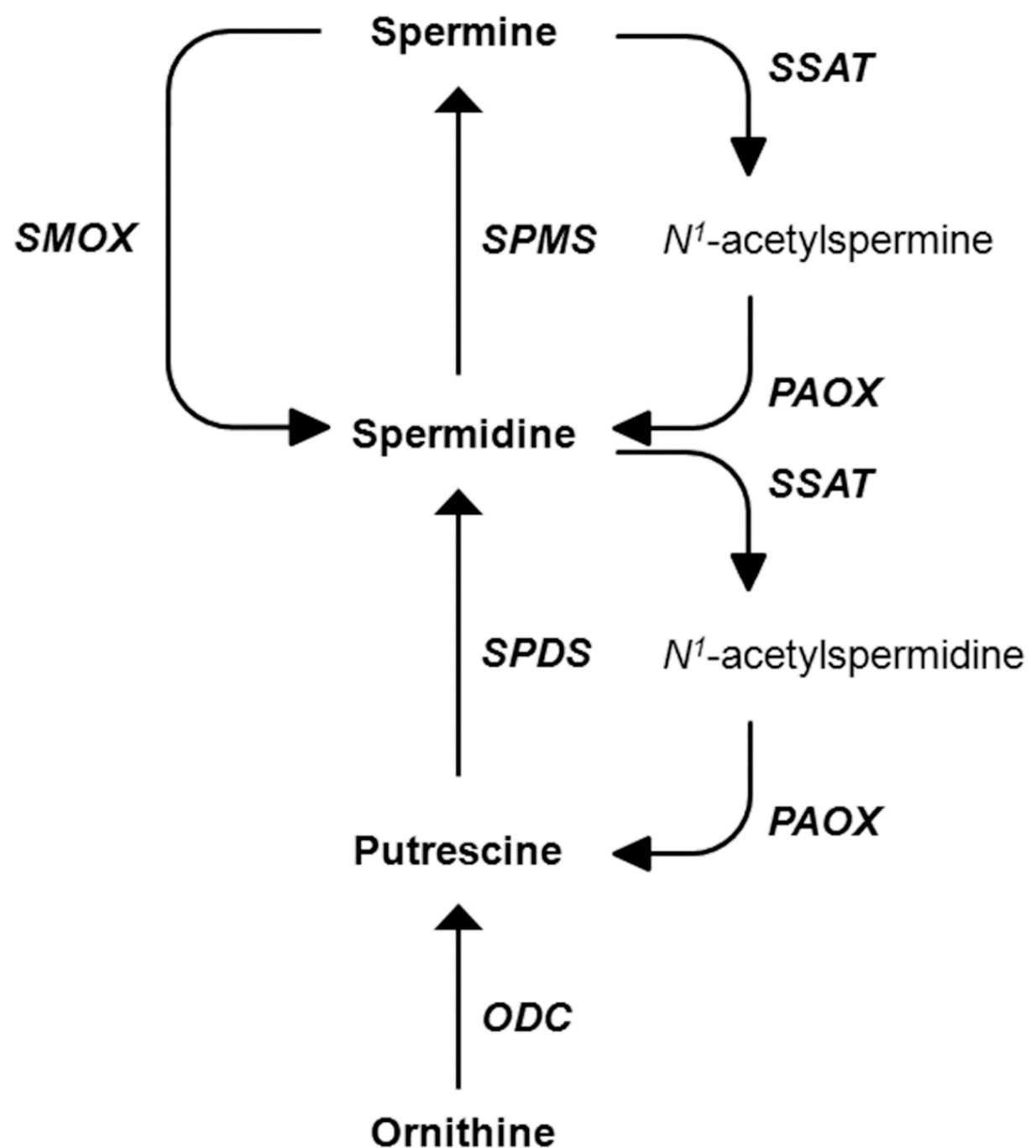

Figure 1. Polyamine metabolism. Schematic representation of mammalian polyamine metabolism showing enzyme network and substrate interconversion pathways. ODC: ornithine decarboxylase; SSAT: spermidine/spermine $N^{1}$-acetyltransferase; PAOX: polyamine oxidase; SMOX: spermine oxidase; SPMS: spermine synthase; SPDS: spermidine synthase.

Polyamine levels can be altered by physiological stimuli or by inhibitors or inducers of PA metabolic enzymes. Animal models with genetically altered PA synthesis or catabolism offer a versatile way to affect PA homoeostasis in different tissues and for a prolonged period. These models help to define the physiological importance of PAs by offering tools to develop treatment therapies for pathophysiological conditions derived from deregulated PA homeostasis [10]. Given the role of PAs in the development of many tissues, numerous studies have examined the relation between PAs and skeletal muscle atrophy and hypertrophy. The importance of PAs in muscle disease is highlighted by an alteration of their levels in muscular fibers undergoing degeneration and regeneration [10]. Altered PA levels are present in muscles of patients suffering from Duchenne muscular dystrophy, a pathology characterized by muscle fiber atrophy [11]. Limb girdle dystrophy patients, who display weakness and wasting of the muscles in the arms and legs, show higher levels of PAs in skeletal muscle [11,12]. Similarly, in mouse and hamster models of muscle dystrophy, PA content is altered compared to control muscles [12]. Although the strong association between PA levels and muscle mass is evident, the potential mechanism by which PAs regulate muscle growth is still unclear [10]. This review focuses on the role of SMOX in skeletal muscle pathophysiology, underlining its role in myogenesis and muscle 
atrophy. The use of a Total-SMOX animal model could help to find new therapies able to counteract physiological atrophy due to aging and pathology.

\section{Skeletal Muscle Differentiation}

Skeletal muscle differentiation (myogenesis) is a finely regulated process involving a cascade of muscle-specific genes whose expression is coordinated in a timely manner to cell cycle withdrawal and synthesis of muscle contractile proteins. During embryogenesis, muscle fibers are established through a highly ordered multistep process leading from mononucleated-undifferentiated cells (myoblasts) to polynuclear cells (myotubes) [13]. The process is predominantly regulated by myogenic regulatory factors (MRFs) of the basic helix-loop-helix family of transcription factors including MyoD, Myf5, myogenin, and MRF4, together with other transcription factors such as paired box 3 (Pax3) and paired box 7 (Pax7) [14]. MyoD and Myf5, expressed before the onset of myogenic differentiation, promote proliferation and differentiation of myogenic progenitor cells into myoblasts [15], while myogenin plays an important role in the differentiation of myoblasts into myotubes and MRF4 participates in differentiation and cell fate determination [16] (Figure 2).

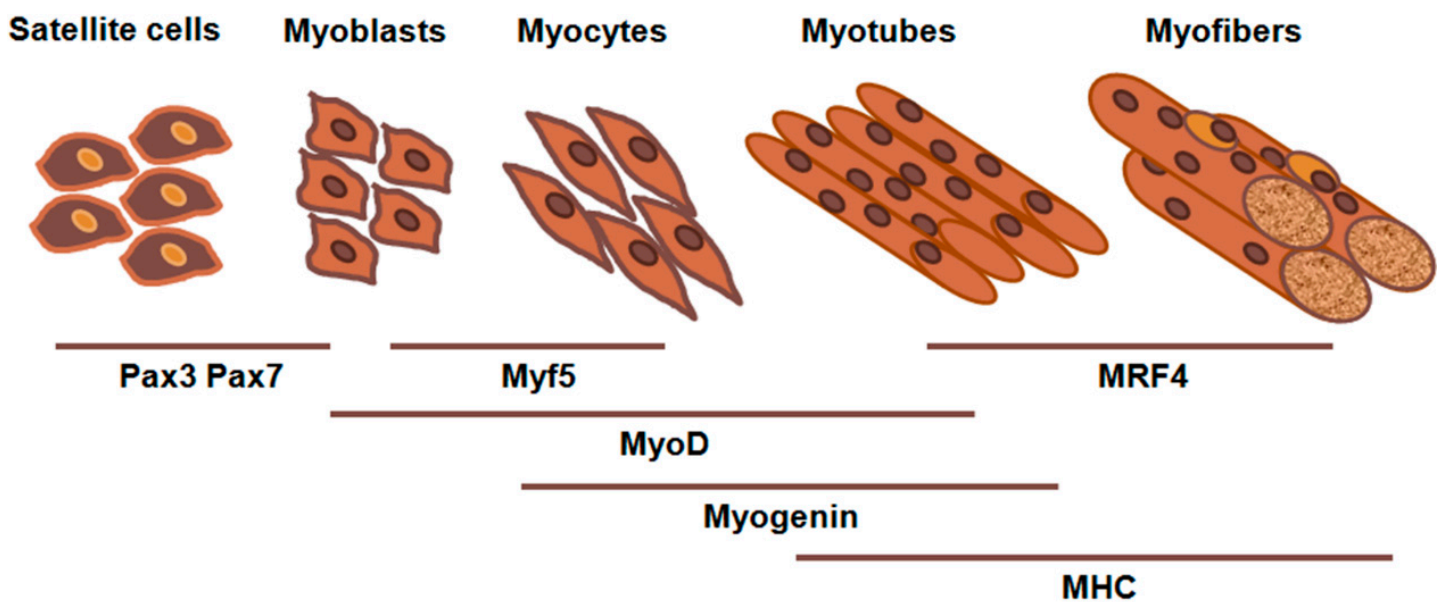

Figure 2. Schematic illustration of the skeletal muscle differentiation process. During myogenesis, Pax3 and Pax7 are activated in quiescent progenitors. Then, progenitor cells differentiate into proliferating muscle precursor cells (myoblasts) and Myf5, MyoD, and myogenin expression stimulates myoblasts to differentiate into myotubes. The terminal stage of differentiation is mediated by the activation of genes responsible for muscle fiber (myofiber) architecture and functionality such as MHCs. Pax: paired box; Myf5: myogenic factor 5; MyoD: myogenic factor 3; MRF4: myogenic regulatory factor 4; MHC: myosin heavy chain.

It must be pointed out that exiting from the cell cycle is a critical regulatory event for successful myogenic differentiation. The elevation of MyoD expression in proliferating myoblasts induces transcriptional upregulation of cell-cycle inhibitors, such as the cyclin-dependent kinase inhibitor p21, that play a fundamental role in establishing the post-mitotic state in skeletal muscle, completing the differentiation process $[17,18]$. After cell cycle arrest, late differentiation markers such as myosin heavy chain (MHC) are induced [19] (Figure 2).

During adulthood, constant muscle remodeling is possible due to the presence of a specialized population of myogenic progenitors, the satellite cells, placed underneath the myofiber basal lamina. These cells, mitotically quiescent, act as muscle stem cells, allowing the repair and maintenance of myofibers. Upon damage or stress, satellite cells divide asymmetrically: some of them reconstitute the pool of quiescent satellite stem cells and others differentiate into myoblasts. Finally, they fuse together to form new myotubes or fuse with damaged myotubes to repair them [19]. The mouse C2C12 muscle cell line is a useful model system to study the differentiation process. In vitro, myogenic differentiation 
can be obtained by serum deprivation from myoblast cultures. In high serum, myoblasts proliferate, while after serum removal, they go into an early differentiation stage. Later, cells begin to fuse, forming multinucleated myotubes positive for the characteristic muscle-specific protein MHC [20-22].

Many molecules are highly regulated during the phenotypic conversion of rapidly dividing $\mathrm{C} 2 \mathrm{C} 12$ myoblasts into fully differentiated post-mitotic myotubes. Among them, SMOX, the most recently characterized polyamine catabolic enzyme [23], has been shown to be modulated during C2C12 differentiation [24].

\section{Spermine Oxidase and Muscle Tissue}

In animal cells, SMOX can be considered a multitasking enzyme, primarily involved in controlling PA metabolism, and its substrate Spm and reaction product Spd are ubiquitous polycations that have several important control functions in cells, ranging from basic DNA synthesis to regulation of cell proliferation and differentiation [25].

The SMOX gene is highly expressed in muscle tissue, as demonstrated by Cervelli et al. [26], who reported a high level of both transcript and enzymatic activity. Interestingly, in C2C12 myoblast cultures, after serum removal, SMOX messenger RNA (mRNA) activity was downregulated in the early stage of differentiation. Successively, SMOX was induced in a time-dependent manner, at the level of both transcription and enzymatic activity. Overall, the pattern of SMOX expression profile in the $\mathrm{C} 2 \mathrm{C} 12$ muscle cell line showed high levels in proliferating myoblasts followed by low levels in differentiating myoblasts and high levels again in myocytes/myotubes [24].

The relatively high expression levels of SMOX in proliferating cells could promote cell expansion and/or survival. It is known that SMOX can be rapidly induced in response to stress and is responsible for $\mathrm{H}_{2} \mathrm{O}_{2}$ production in different cell lines and malignant tissues [27]. Thus, a decrease in its activity, and possibly a reduction in the level of $\mathrm{H}_{2} \mathrm{O}_{2}$, could allow for subsequent cell differentiation, with fully differentiated cells resuming its expression and activity. A failure of SMOX downregulation might result in defective differentiation and potentially contribute to neoplastic transformation. It is interesting that SMOX expression levels are high in several tumor cell types [28,29]. Hence, there needs to be investigation of mechanisms through which SMOX expression can be re-established, as occurs at the end of the differentiation process. Interestingly, a recent study suggested that muscle atrophy induced by limb immobilization, fasting, muscle denervation, and aging could be related to a significant reduction of SMOX expression, while on the other hand, when SMOX was overexpressed, muscle fiber size increased. Furthermore, SMOX overexpression resulted in a decrease of the genes that promote muscle atrophy and, conversely, an increase in the expression of genes that help to maintain muscle mass [30]. Overall, these results highlight the importance of SMOX in the pathophysiology of skeletal muscle. Remarkably, involvement of p21 has been observed in atrophy conditions: the induction of p21 actively promotes muscle atrophy, leading to reduced SMOX expression; on the other hand, a relatively low level of p21 allows a higher level of SMOX expression, which helps to maintain basal skeletal muscle gene expression and fiber size [30]. It has been reported that p21 plays an important role in the in vivo healing process in muscular injury [31], and moreover, it has been shown that p21 protein is modulated during $\mathrm{C} 2 \mathrm{C} 12$ differentiation: it increases at cell cycle exit and entrance into differentiation and declines in a time-dependent manner thereafter [32].

In Figure 3, a hypothetical scheme shows the possible relation between SMOX and p21 during myogenesis. 
p21

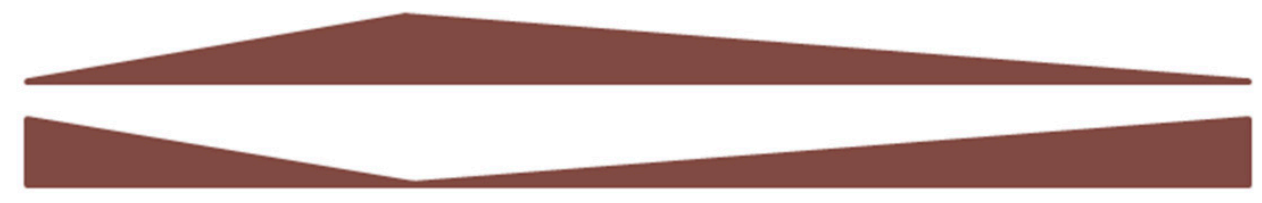

SMOX

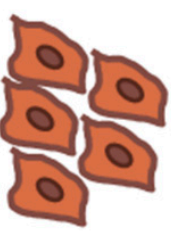

Myoblasts

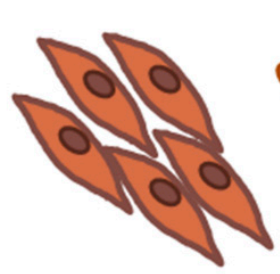

Myocytes

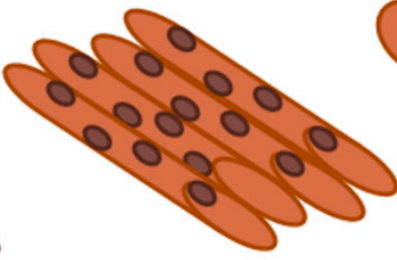

Myotubes

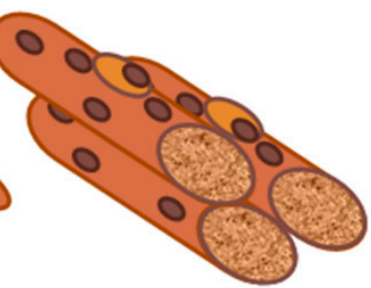

Myofibers

Figure 3. Hypothetical representation of SMOX regulation during myogenesis. During the early stage of muscle differentiation, p21 expression increases, leading to reduced SMOX expression. During the differentiation process, p21 declines in a time-dependent manner, allowing SMOX expression.

Spermine oxidase catalyzes the direct back-conversion of Spm to Spd, 3-aminopropanal (3-AP), which is non-enzymatically converted to acrolein, and hydrogen peroxide $\left(\mathrm{H}_{2} \mathrm{O}_{2}\right)$ (Figure 4), and each of these products can affect muscle tissue in various ways, as described in the following sections.

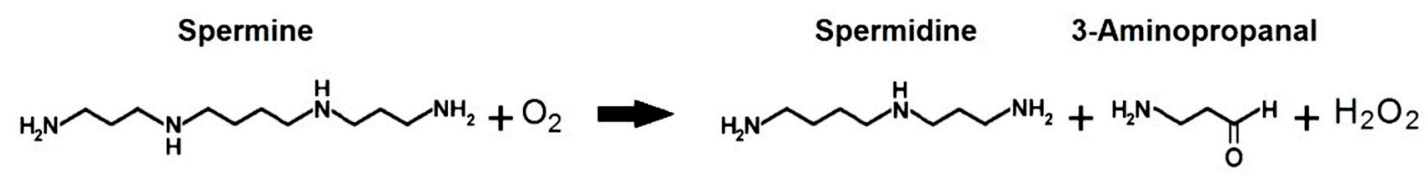

Figure 4. Enzymatic reaction catalyzed by SMOX. The physiological substrate spermine (Spm) is oxidized by the SMOX enzyme into spermidine (Spd) with the production of 3-aminopropanal and hydrogen peroxide.

\section{Hydrogen Peroxide and Muscle Tissue}

The reactive oxygen species (ROS) $\mathrm{H}_{2} \mathrm{O}_{2}$ produced by SMOX is a two-electron, nonradical oxidant molecule that is stable and freely diffuses within and between cells, and therefore acts as a signaling molecule. Numerous studies on myogenesis have indicated that muscle development is particularly sensitive to environmental and endogenous $\mathrm{H}_{2} \mathrm{O}_{2}$ levels. On the whole, $\mathrm{H}_{2} \mathrm{O}_{2}$ is directly engaged in modulating the expression of several enzymes related to the cellular redox state and plays a wide range of important roles in a variety of cells in a concentration-dependent manner [33-36]. It is to be noted that at low concentrations, $\mathrm{H}_{2} \mathrm{O}_{2}$ can activate various enzymes, such as phosphatases, modulating cell signaling; on the other hand, at high concentrations, it causes oxidative stress, leading to irreversible cell damage [37].

Some studies, conducted by treating cells with $\mathrm{H}_{2} \mathrm{O}_{2}$ exogenously, provide evidence for its negative effect on myoblast differentiation. Treatment with $\mathrm{H}_{2} \mathrm{O}_{2}$ slowed differentiation [38] and reduced myogenin and MHC protein content and creatine kinase activity, as well as troponin I gene transcription, in a dose-dependent manner [39]. The inhibition of myotube formation was reversible when the powerful antioxidant $N$-acetylcysteine had been previously added to the culture medium [39]. It was also reported that $\mathrm{H}_{2} \mathrm{O}_{2}$ administration markedly reduced Myf5, MRF4 gene, and myogenin expression [40]. Another study showed that during the early stages of C2C12 myoblast differentiation, mildly toxic treatment with $\mathrm{H}_{2} \mathrm{O}_{2}$ resulted in the depletion of glutathione (GSH), the main thiol antioxidant, leading to further intracellular accumulation of ROS. The oxidative environment favored the activation of nuclear factor-kappa B (NF- $\mathrm{B}$ ), a redox-sensitive transcription factor, thus contributing to the lower expression of MyoD and impaired myogenesis [41]. 
On the other hand, other studies have shown a crucial role for endogenous ROS concentrations during skeletal muscle differentiation. It has been reported that an increase in skeletal muscle NADPH oxidase isoform 2 (NOX2) activity during differentiation leads to a rise in superoxide anion $\mathrm{O}_{2}{ }^{-}$, a molecule quickly converted by dismutation into $\mathrm{H}_{2} \mathrm{O}_{2}$. In line with the positive role of ROS, this increase seems to be crucial to muscle differentiation via NF- $\mathrm{kB}$ /inducible nitric oxide synthase (iNOS) pathway activation [42] and to the promotion of skeletal muscle precursor cell proliferation [43]. Furthermore, it has been observed that enhancement of the endogenous $\mathrm{H}_{2} \mathrm{O}_{2}$ level can regulate the cellular GSH redox balance from the very early stage to the fully differentiated myotube formation stage [44]. On the whole, these data clearly show that myogenesis is a process very sensitive to the intracellular redox environment, and at the same time supports the notion that $\mathrm{H}_{2} \mathrm{O}_{2}$ can have different outcomes depending on its intracellular concentration.

\section{Acrolein and Muscle Tissue}

Numerous conditions, such as oxidative stress, inflammation, alcoholic myopathy, and renal failure in which acrolein is increased, have been associated with muscle deterioration and dysfunction, resulting in disease. Moreover, increased muscle catabolism has been linked to an exogenous source of acrolein due to cigarette smoking [45]. Exposure of skeletal myotubes to cigarette smoke stimulates muscle catabolism via increased oxidative stress, activation of $\mathrm{p} 38$ mitogen-activated protein kinases (p38MAPK), and upregulation of muscle-specific E3 ubiquitin ligases [45]. In addition, acrolein treatment was sufficient to induce an increase of free radicals, activation of p38 MAPK, up-regulation of the muscle-specific E3 ligases atrogin-1 and MuRF1, degradation of MHC, and atrophy of myotubes. Inhibition of p38MAPK by SB203580 abolished acrolein-induced muscle catabolism [46]. These studies demonstrated that acrolein is able to activate a signaling cascade, inducing muscle catabolism in skeletal myotubes. Acrolein can also react with amino acid residues in proteins, consequently modifying protein function and inducing apoptosis [47] or tissue damage such as brain infarction $[48,49]$. Notwithstanding that high levels of acrolein within cells have been linked to toxicity, it has recently been demonstrated that SMOX plays a central role in the formation of bile canalicular lumen in liver cells by activating the protein kinase B (AKT) pathway through acrolein production [50].

\section{Spermidine and Muscle Tissue}

Considering the new emerging role of SMOX in muscle physiology, it is of primary importance to have full knowledge of this enzyme and the role of its catabolic product Spd. In several model systems such as yeast, flies, worms, and human immune cells, Spd levels decrease during aging, and by giving Spd as a dietary supplement, lifespan is extended [51]. In fact, a Spd-rich diet postpones age-related phenomena, such as the progressive decline of locomotor activity in flies [52]. In this variety of model organisms, Spd was found to suppress several aging-associated parameters, such as overproduction of ROS and the level of necrotic cell death [51]. Recently, Spd has been of great interest in the prevention or treatment of muscle diseases, since it may play a role in skeletal muscle atrophy/hypertrophy [53]. Aging brings a loss of skeletal muscle, and it has been shown that Spd cellular concentrations decrease during age progression [51]. Autophagy contributes to age-related degeneration processes, since it has been proven to decrease with aging. In physiological conditions, autophagy has a critical role, acting as a cell housekeeper by degrading damaged or unnecessary organelles and allowing the recovery of metabolites under nutrient starvation [54,55]. Deregulated autophagy contributes to neurodegenerative disorders, as well as liver, heart, and muscle diseases [56]. Variations in autophagic flux have been demonstrated to affect muscle homeostasis and body metabolic state [56]. Different studies have analyzed the correlation between aging, Spd, and autophagy and led to the identification of Spd as a strong and specific inducer of autophagy [56]. Through the autophagy mechanism, Spd extends lifespan by triggering epigenetic deacetylation of histone $\mathrm{H} 3$ through inhibition of histone acetyltransferases, suppressing oxidative stress and necrosis [51]. This mechanism provides protection from the aging process for several tissues, including heart, brain, and skeletal muscle, thereby endorsing 
longevity [1]. In an aged population, regular and proper exercise is used as a stimulus for muscle adaptation, attenuating the loss of skeletal muscle [57]. Autophagy attenuation that occurs with aging has been shown to be reduced with exercise training, thus endurance exercise enhances autophagic signaling in aged mice [1]. The coupled use of a specific autophagic inducer such as Spd and regular exercise could activate autophagy, establishing a correct health level for the maintenance of skeletal muscle [1].

Extended bed rest or post-surgery immobilization, resulting in skeletal muscle unloading, leads to skeletal muscle atrophy. In addition, exposure to a microgravity environment during extended space flights brings skeletal muscle disuse/atrophy similar to what is observed in prolonged bed rest or post-surgery recovery [53]. Abukhalaf et al. [53] reported that skeletal muscle polyamine levels appear to be influenced by microgravity (hind limb suspension) in a fiber-type-specific manner. Unloading-induced atrophy was accompanied by a dramatic decrease in Spd level (68\%) in slow-twitch (type I) muscle fibers, but a slight increase (14\%) in fast-twitch (type II) ones, when comparing unloaded and control animals [53]. No significant changes were observed in Spm levels in either type of muscle fibers [53]. On the other hand, individuals suffering from myasthenia gravis display high Spd and Spm levels, associated with muscle weakness and severe atrophy [58]. Further contrasting results were obtained by Bongers et al. [30], who did not detect any change of Spd levels in limb immobilization, suggesting that enzymes other than SMOX or transporters are able to maintain Spd levels when SMOX activity is reduced. Taking into account all these works, it can be seen that the direct role of polyamines, and in particular Spd, needs to be clarified in detail, but it is necessary to refer to the specific type of muscle fiber in light of the results obtained by Abukhalaf et al. [53].

A frequently used model to induce aging-related damage in vivo is administration of D-galactose (D-gal) [59], which causes accumulation of ROS with final oxidative stress [60].

Excessive apoptosis and deficient autophagy may cause skeletal muscle atrophy due to pathological events or the aging process, thus promoting cell death and disease progression [1]. Recently, AMP-activated protein kinase (AMPK) has been found to phosphorylate forkhead box O3 (FOXO3a) on Ser588 [61]. The FOXO3a signaling pathway induces the transcriptional activation of autophagy-related genes that oversee protein degradation. FOXO3a was found to be necessary for the reduction of skeletal muscle atrophy induced by D-gal and to maintain proliferation in aging skeletal muscle cells by Spd and exercise. These results suggest that exercise and Spd may share mediators that act on similar pathways in varying degrees, generating a synergistic effect for delaying skeletal muscle senescence [1]. Therefore, $\mathrm{Spd}$, by activating the AMPK-dependent autophagy pathway, may decrease endoplasmic reticulum stress and reduce apoptosis [62].

Skeletal muscle atrophy is a state that not only characterizes a physiological condition in the aged population or in extended bed rest, but also is present in several pathologies with different etiologies.

Spermidine was found to ameliorate myopathic defects in the animal model of Ullrich congenital muscular dystrophy (UCMD) and Bethlem myopathy (BM) (col6a1 $1^{-/-}$mice) by reactivating autophagy in skeletal muscle [56]. In this model, there is overactivation of AKT, which causes defective autophagy by activating the mechanistic target of rapamycin, which inhibits the transcription of genes under FOXO [56]. Ineffective autophagy brings an accumulation of damaging organelles in the myofibers, which degenerate with time. However, this process is reversible through dietary and pharmacological approaches [63]. The beneficial effects of Spd administration in col6a1 $1^{-/}$mice are linked to its ability to reactivate autophagic flux [64], as demonstrated by a significant increase of LC3B and autophagosome formation [56]. Spermidine seems to act on AKT [56]. AKT kinase negatively regulates, by phosphorylation, the activity of FOXO transcriptional factors. Low levels of phosphorylated AKT activate FOXO [65]. Spermidine is able to reduce AKT phosphorylation, which triggers the translocation of FOXO transcriptional factors into the nucleus, promoting autophagy [56]. BM and UCMD patients display respiratory insufficiency due to a loss of diaphragm function [66], which is also the most affected muscle in col6a1 $1^{-/-}$mice, where it shows a high incidence of apoptotic myofibers [63]. Spermidine was able to rescue the aspects of both BM and UCMD. 
FOXO proteins are key transcription factors regulated by different post-translational modifications, and among these, inhibitory acetylation by the histone acetyltransferase EP300 has been described in detail [67]. Since Spd also acts as a histone acetyltransferase inhibitor, and one of its known targets is EP300 [68], it is probable that Spd controls FOXO activity at multiple levels and determines a permissive condition for its activity by the action of AMPK, AKT, and EP300 (Figure 5).

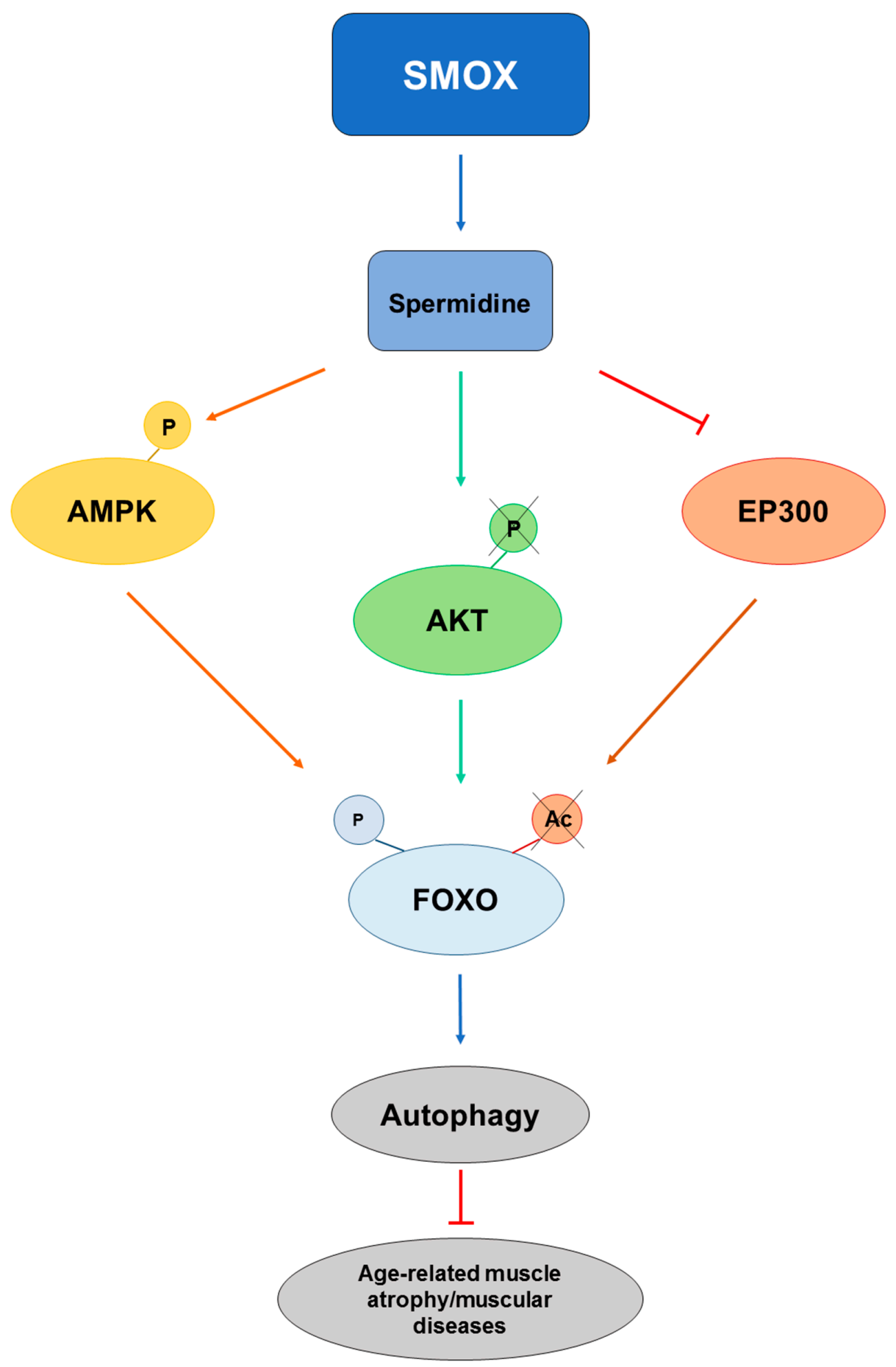

Figure 5. Schematic representation of spermidine effects of on forkhead box (FOXO) activity. The effect of spermidine on the attenuation of age-related skeletal muscle atrophy and diseases, through regulating autophagy via $5^{\prime}$ AMP-activated protein kinase (AMPK)/Protein Kinase B (AKT)/E1A binding protein p300 (EP300)-FOXO signal pathways. 


\section{Polyamines and Muscle Diseases}

The involvement of Spd, and of PAs in general, has also been demonstrated in amyotrophic lateral sclerosis (ALS) and Duchenne muscular dystrophy. Results from ALS patients and SOD1 ${ }^{\text {G93A }}$ mice, an animal model for ALS pathology, showed deregulated PA levels in plasma, skeletal muscle, and cerebral cortex. The many roles of PAs include ALS-relevant processes such as protection against stress induced by ROS [69], modulation of glutamate ion channel receptors [70], and induction of autophagy [51]. Similarly, muscular fibrosis after denervation displays a constant rise in PA concentration [71].

Duchenne muscular dystrophy is a neuromuscular disease caused by mutation(s) in the dystrophin gene. It is characterized by skeletal muscle and cardiopulmonary complications, resulting in shorter life expectancy. The mouse model that better represents this disease is a double-mutant mouse (dmd/utrn double mutant $(m d x-d m))$, where both dystrophin and utrophin genes are mutated [72]. It is hypothesized that the rapid deterioration of muscles is correlated to reduced action of androgens [73]. In a recent study, GTx-026 a nonsteroidal selective-androgen receptor modulator that selectively builds muscle and bone, was used to treat $m d x-d m$ mice, and it was able to increase muscle mass, function, and survival [72]. While GTx-026 failed to reverse the genes altered by dystrophin knockdown, it regulated the expression of several genes of the PA pathway. Interestingly, GTx-026 significantly increased SMOX by two- to threefold. Moreover, genes belonging to the Spd pathway were also upregulated by GTx-026, confirming the crucial role of Spd in enhancing cellular lifespan and proposing SMOX as a key gene in muscle diseases [72].

\section{The Transgenic Mouse Line: Total-Smox}

Spermine oxidase is a significant positive regulator of muscle gene expression and fiber size. Recently, a Cre/loxP-based double transgenic mouse line overexpressing the Smox gene in all organs was engineered and named Total-Smox. Transgenic Green Fluorescent Protein (GFP)-Smox (formerly JoSMOX) mice described by Cervelli et al. [6] were crossed with Total-CRE mice reported by [74], to obtain the Total-Smox genetic line (Figure 6). This new experimental model was further genetically stabilized by back-crossing Total-Smox mice 10 times with C57BL/ 6 mice. SMOX overexpression in transgenic individuals can be detected in all tissues by $\beta$-Galoctiside (3-Gal) staining (Figure 6) and reverse-transcriptase/PCR analysis. As expected, SMOX enzyme activity was higher in all the organs of Total-Smox mice in comparison to their syngenic littermates, including skeletal muscle and heart, as demonstrated by [75].

A

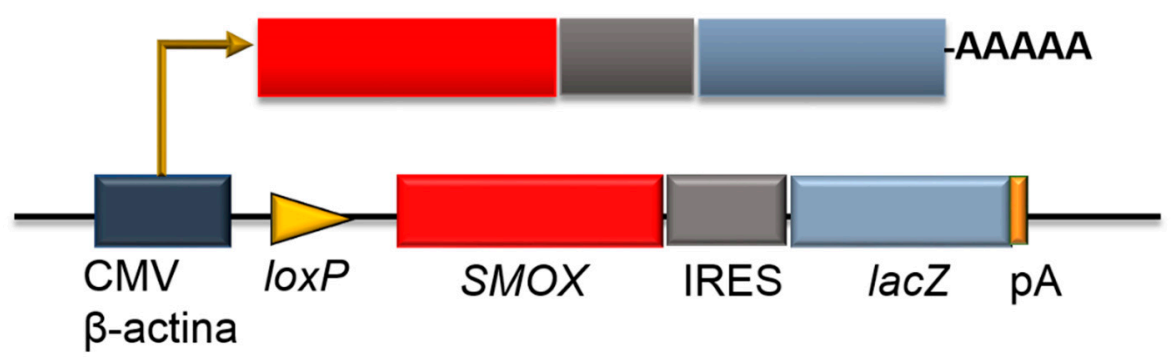

B

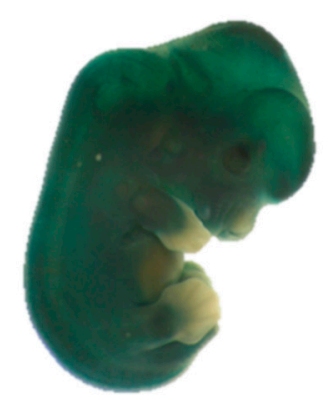

Figure 6. Total-Smox mouse line. (A) Scheme of the genetic construct of the Total-Smox mouse line upon recombination of the loxP sites by Cre recombinase. The $\beta$-actin/Cytomegalovirus (CMV) fusion promoter drives the ubiquitous expression of the SMOX gene and the lacZ reporter gene. IRES: internal ribosome entry site. (B) LacZ staining of Total-Smox embryo. 
In the literature, it is known that muscle diseases and aging-related pathologies display high oxidative stress by accumulating $\mathrm{H}_{2} \mathrm{O}_{2}$ in the muscles [76]. In the Total-Smox mouse model, chronic $\mathrm{H}_{2} \mathrm{O}_{2}$ production due to SMOX overexpression leads to an imbalanced cellular redox state in both types of muscle tissue. Skeletal muscle displays lower oxidative damage compared to the heart, evoking a different redox adaptation through upregulation of the enzymatic antioxidant system [75]. This tissue shows a significant decline in the ratio of GSH reduced and oxidized due to a decrease in the total amount of GSH. SMOX overexpression increases glutathione S-transferase activity, since it is an enzyme induced under oxidative stress and is responsible for the detoxification of molecules through the formation of S-conjugates [75]. SMOX overexpression in the skeletal muscle of Total-Smox mice also causes a concomitant increase of catalase, another detoxifying enzyme, indicating that there is a counteracting action against the high $\mathrm{H}_{2} \mathrm{O}_{2}$ production. Moreover, the amount of Spd has been found to be elevated in Total-Smox mice compared to control animals, while the levels of Put and Spm were not altered. Spermidine has been proven to be essential in muscle physiology by promoting autophagy, counteracting aging, and extending lifespan [1].

Considering the important role of Spd in many pathologies and that Spd increases in the Total-Smox mice model while no changes are reported for the other PAs, it would be interesting to cross this mouse line with animal models of different diseases such as Ullrich congenital muscular dystrophy and Bethlem myopathy (col6a1 ${ }^{-/-}$mice), amyotrophic lateral sclerosis (SOD1 ${ }^{\mathrm{G} 93 \mathrm{~A}}$ mice), and Duchenne muscular dystrophy ( $m d x-d m$ mice), to evaluate the possibility of rescuing the phenotype.

\section{Conclusions and Future Perspectives}

This review points out that not only does SMOX take part in cancer and neurological disorders, but it is also involved in skeletal muscle pathophysiology. New evidence for the physiological roles of the PA pathway in atrophy could represent a major area for future research [77]. The prevalence rate of sarcopenia is up to $33 \%$ in elderly people, and the number is expected to increase due to lifestyle, dietary habits, and aging [78]. It has been known that PA levels and related enzyme activities decline during aging; however, until recently, it was not clear how alterations in PA metabolism could affect the aging process [79]. Several experiments have highlighted the role of Spd as an autophagy inducer that ameliorates age-related muscle atrophy [80]. Different mouse models of disease have brought new insights as to the possibility of Spd as a therapeutic food option. This approach could be used to design innovative treatments, with Spd alone or in combination with other approaches, leading to clinical trials. In perspective, this nutraceutical-based, autophagy-inducing approach could be applied to different therapies, and could also be extended to other inherited muscle pathologies involving defective activity of the autophagy machinery. Of note, Spd is the reaction product of SMOX, which in turn has been demonstrated to help in maintaining muscle mass and counteracting the expression of genes that promote muscle atrophy. Understanding how the SMOX/p21 axis and its product Spd influence muscle gene expression and how they are linked to autophagy and muscular atrophy during aging is a new field of investigation. Considering that SMOX is highly expressed in skeletal muscle and regulates the amount of PAs, it can become a key gene to target for treatment of diseases such as Duchenne muscular dystrophy.

In perspective, Total-Smox mice could be considered as a valuable genetic animal model to investigate the role of SMOX and Spd in muscular physiology, shedding light on new therapies to test in several muscle diseases.

Acknowledgments: The authors wish to thank Rosetta Ponzo for revision of the English text. This work was supported by grants from the Università degli Studi di Roma "Foro Italico" (DIP DSS10-15 and DIP DSS08-16) to S.S. and the Università degli Studi di Roma "Roma Tre" contribution to the laboratories (CAL/2016) to M.C. and P.M. and by the Ph.D. School (Department of Science) contribution 2017 to A.L.

Author Contributions: All authors contributed equally to the conception of this review.

Conflicts of Interest: The authors declare no conflict of interest. 


\section{References}

1. Fan, J.; Yang, X.; Li, J.; Shu, Z.; Dai, J.; Liu, X.; Li, B.; Jia, S.; Kou, X.; Yang, Y.; et al. Spermidine coupled with exercise rescues skeletal muscle atrophy from D-gal-induced aging rats through enhanced autophagy and reduced apoptosis via AMPK-FOXO3a signal pathway. Oncotarget 2017, 8, 17475-17490. [CrossRef] [PubMed]

2. Ali, S.; Garcia, J.M. Sarcopenia, cachexia and aging: Diagnosis, mechanisms and therapeutic options-a mini-review. Gerontology 2014, 60, 294-305. [CrossRef] [PubMed]

3. Rea, G.; Bocedi, A.; Cervelli, M. What is the biological function of the polyamines? IUBMB Life 2004, 56, 167-169. [CrossRef] [PubMed]

4. Cervelli, M.; Angelucci, E.; Germani, F.; Amendola, R.; Mariottini, P. Inflammation, carcinogenesis and neurodegeneration studies in transgenic animal models for polyamine research. Amino Acids 2014, 46, 521-530. [CrossRef] [PubMed]

5. Cervelli, M.; Bellavia, G.; Fratini, E.; Amendola, R.; Polticelli, F.; Barba, M.; Rodolfo, F.; Signore, F.; Gucciardo, G.; Grillo, R.; et al. Spermine oxidase (SMO) activity in breast tumor tissues and biochemical analysis of the anticancer spermine analogues BENSpm and CPENSpm. BMC Cancer 2010, 10, 555-564. [CrossRef] [PubMed]

6. Cervelli, M.; Bellavia, G.; D’amelio, M.; Cavallucci, V.; Moreno, S.; Berger, J.; Nardacci, R.; Marcoli, M.; Maura, G.; Piacentini, M.; et al. A New Transgenic Mouse Model for Studying the Neurotoxicity of Spermine Oxidase Dosage in the Response to Excitotoxic Injury. PLoS ONE 2013, 8, e64810. [CrossRef] [PubMed]

7. Cervelli, M.; Pietropaoli, S.; Signore, F.; Amendola, R.; Mariottini, P. Polyamines metabolism and breast cancer: State of the art and perspectives. Breast Cancer Res. Treat. 2014, 148, 233-248. [CrossRef] [PubMed]

8. Cervelli, M.; Leonetti, A.; Cervoni, L.; Ohkubo, S.; Xhani, M.; Stano, P.; Federico, R.; Polticelli, F.; Mariottini, P.; Agostinelli, E. Stability of spermine oxidase to thermal and chemical denaturation: Comparison with bovine serum amine oxidase. Amino Acids 2016, 48, 2283-2291. [CrossRef] [PubMed]

9. Cervetto, C.; Vergani, L.; Passalacqua, M.; Ragazzoni, M.; Venturini, A.; Cecconi, F.; Berretta, N.; Mercuri, N.; D'Amelio, M.; Maura, G.; et al. Astrocyte-Dependent Vulnerability to Excitotoxicity in Spermine Oxidase-Overexpressing Mouse. Neuromol. Med. 2016, 18, 50-68. [CrossRef] [PubMed]

10. Lee, N.K.; MacLean, H.E. Polyamines, androgens, and skeletal muscle hypertrophy. J. Cell. Physiol. 2011, 226, 1453-1460. [CrossRef] [PubMed]

11. Kaminska, A.M.; Stern, L.Z.; Russell, D.H. Altered muscle polyamine levels in human neuromuscular diseases. Ann. Neurol. 1981, 9, 605-607. [CrossRef] [PubMed]

12. Rudman, D.; Kutner, M.H.; Chawla, R.K.; Goldsmith, M.A. Abnormal polyamine metabolism in hereditary muscular dystrophies: Effect of human growth hormone. J. Clin. Investig. 1980, 65, 95-102. [CrossRef] [PubMed]

13. Hernández-Hernández, J.M.; García-González, E.G.; Brun, C.E.; Rudnicki, M.A. The myogenic regulatory factors, determinants of muscle development, cell identity and regeneration. Semin. Cell Dev. Biol. 2017, 72, 10-18. [CrossRef] [PubMed]

14. Soleimani, V.D.; Punch, V.G.; Kawabe, Y.; Jones, A.E.; Palidwor, G.A.; Porter, C.J.; Cross, J.W.; Carvajal, J.J.; Kockx, C.E.; van IJcken, W.F.; et al. Transcriptional dominance of Pax7 in adult myogenesis is due to high-affinity recognition of homeodomain motifs. Dev. Cell 2012, 22, 1208-1220. [CrossRef] [PubMed]

15. Gianakopoulos, P.J.; Mehta, V.; Voronova, A.; Cao, Y.; Yao, Z.; Coutu, J.M.; Wang, X.; Waddington, M.S.; Tapscott, S.J.; Skerjanc, I.S. MyoD directly up-regulates premyogenic mesoderm factors during induction of skeletal myogenesis in stem cells. J. Biol. Chem. 2011, 286, 2517-2525. [CrossRef] [PubMed]

16. Kassar-Duchossoy, L.; Gayraud-Morel, B.; Gomès, D.; Rocancourt, D.; Buckingham, M.; Shinin, V.; Tajbakhsh, S. Mrf4 determines skeletal muscle identity in Myf5: Myod double-mutant mice. Nature 2004, 431, 466-471. [CrossRef] [PubMed]

17. Ishido, M.; Kami, K.; Masuhara, M. In vivo expression patterns of MyoD, p21, and Rb proteins in myonuclei and satellite cells of denervated rat skeletal muscle. Am. J. Physiol. Cell Physiol. 2004, 287, 484-493. [CrossRef] [PubMed]

18. Wei, Q.; Paterson, B.M. Regulation of MyoD function in the dividing myoblast. FEBS Lett. 2001, 490, 171-178. [CrossRef] 
19. Zanou, N.; Gailly, P. Skeletal muscle hypertrophy and regeneration: Interplay between the myogenic regulatory factors (MRFs) and insulin-like growth factors (IGFs) pathways. Cell. Mol. Life Sci. 2013, 70, 4117-4130. [CrossRef] [PubMed]

20. Duranti, G.; La Rosa, P.; Dimauro, I.; Wannenes, F.; Bonini, S.; Sabatini, S.; Parisi, P.; Caporossi, D. Effects of salmeterol on skeletal muscle cells: Metabolic and pro-apoptotic features. Med. Sci. Sports Exerc. 2011, 43, 2259-2273. [CrossRef] [PubMed]

21. Ceci, R.; Duranti, G.; Rossi, A.; Savini, I.; Sabatini, S. Skeletal muscle differentiation: Role of dehydroepiandrosterone sulfate. Horm. Metab. Res. 2011, 43, 702-707. [CrossRef] [PubMed]

22. Duranti, G.; Ceci, R.; Sgrò, P.; Sabatini, S.; Di Luigi, L. Influence of the PDE5 inhibitor tadalafil on redox status and antioxidant defense system in C2C12 skeletal muscle cells. Cell Stress Chaperones 2017, 22, 389-396. [CrossRef] [PubMed]

23. Cervelli, M.; Amendola, R.; Polticelli, F.; Mariottini, P. Spermine oxidase: Ten years after. Amino Acid 2012, 42, 441-450. [CrossRef] [PubMed]

24. Cervelli, M.; Fratini, E.; Amendola, R.; Bianchi, M.; Signori, E.; Ferraro, E.; Lisi, A.; Federico, R.; Marcocci, L.; Mariottini, P. Increased spermine oxidase (SMO) activity as a novel differentiation marker of myogenic C2C12 cells. Int. J. Biochem. Cell Biol. 2009, 41, 934-944. [CrossRef] [PubMed]

25. Pegg, A.E. Functions of Polyamines in Mammals. J. Biol. Chem. 2016, 291, 14904-14912. [CrossRef] [PubMed]

26. Cervelli, M.; Bellini, A.; Bianchi, M.; Marcocci, L.; Nocera, S.; Polticelli, F.; Federico, R.; Amendola, R.; Mariottini, P. Mouse spermine oxidase gene splice variants. Nuclear subcellular localization of a novel active isoform. Eur. J. Biochem. 2004, 271, 760-770. [CrossRef] [PubMed]

27. Pledgie, A.; Huang, Y.; Hacker, A.; Zhang, Z.; Woster, P.M.; Davidson, N.E.; Casero, R.A., Jr. Spermine oxidase $\mathrm{SMO}(\mathrm{PAOh} 1)$, Not $N^{1}$-acetylpolyamine oxidase $\mathrm{PAO}$, is the primary source of cytotoxic $\mathrm{H}_{2} \mathrm{O}_{2}$ in polyamine analogue-treated human breast cancer cell lines. J. Biol. Chem. 2005, 280, 39843-39851. [CrossRef] [PubMed]

28. Park, M.H.; Igarashi, K. Polyamines and their metabolites as diagnostic markers of human diseases. Biomol. Ther. (Seoul) 2013, 21, 1-9. [CrossRef] [PubMed]

29. Murray-Stewart, T.R.; Woster, P.M.; Casero, R.A., Jr. Targeting polyamine metabolism for cancer therapy and prevention. Biochem. J. 2016, 473, 2937-2953. [CrossRef] [PubMed]

30. Bongers, K.S.; Fox, D.K.; Kunkel, S.D.; Stebounova, L.V.; Murry, D.J.; Pufall, M.A.; Ebert, S.M.; Dyle, M.C.; Bullard, S.A.; Dierdorff, J.M.; et al. Spermine oxidase maintains basal skeletal muscle gene expression and fiber size and is strongly repressed by conditions that cause skeletal muscle atrophy. Am. J. Physiol. Endocrinol. Metab. 2015, 308, 144-158. [CrossRef] [PubMed]

31. Chinzei, N.; Hayashi, S.; Ueha, T.; Fujishiro, T.; Kanzaki, N.; Hashimoto, S.; Sakata, S.; Kihara, S.; Haneda, M.; Sakai, Y.; et al. p21 deficiency delays regeneration of skeletal muscular tissue. PLoS ONE 2015, 10, e0125765. [CrossRef] [PubMed]

32. Boonstra, K.; Bloemberg, D.; Quadrilatero, J. Caspase-2 is required for skeletal muscle differentiation and myogenesis. Biochim. Biophys. Acta 2018, 1865, 95-104. [CrossRef] [PubMed]

33. Higuchi, M.; Dusting, G.J.; Peshavariya, H.; Jiang, F.; Hsiao, S.T.; Chan, E.C.; Liu, G.S. Differentiation of human adipose-derived stem cells into fat involves reactive oxygen species and Forkhead box $\mathrm{O} 1$ mediated upregulation of antioxidant enzymes. Stem Cells Dev. 2013, 22, 878-888. [CrossRef] [PubMed]

34. Huang, L.S.; Jiang, P.; Feghali-Bostwick, C.; Reddy, S.P.; Garcia, J.G.N.; Natarajan, V. Lysocardiolipin acyltransferase regulates TGF- $\beta$ mediated lung fibroblast differentiation. Free Radic. Biol. Med. 2017, 112, 162-173. [CrossRef] [PubMed]

35. Subramani, B.; Subbannagounder, S.; Ramanathanpullai, C.; Palanivel, S.; Ramasamy, R. Impaired redox environment modulates cardiogenic and ion-channel gene expression in cardiac-resident and non-resident mesenchymal stem cells. Exp. Biol. Med. 2017, 242, 645-656. [CrossRef] [PubMed]

36. Katz, A. Role of reactive oxygen species in regulation of glucose transport in skeletal muscle during exercise. J. Physiol. 2016, 594, 2787-2794. [CrossRef] [PubMed]

37. Kozakowska, M.; Pietraszek-Gremplewicz, K.; Jozkowicz, A.; Dulak, J. The role of oxidative stress in skeletal muscle injury and regeneration: Focus on antioxidant enzymes. J. Muscle Res. Cell Motil. 2015, 36, 377-393. [CrossRef] [PubMed]

38. Hansen, J.M.; Klass, M.; Harris, C.; Csete, M. A reducing redox environment promotes C2C12 myogenesis: Implications for regeneration in aged muscle. Cell Biol. Int. 2007, 31, 546-553. [CrossRef] [PubMed] 
39. Langen, R.C.; Schols, A.M.; Kelders, M.C.; Van Der Velden, J.L.; Wouters, E.F.; Janssen-Heininger, Y.M. Tumor necrosis factor- $\alpha$ inhibits myogenesis through redox-dependent and independent pathways. Am. J. Physiol. Cell Physiol. 2002, 283, C714-C721. [CrossRef] [PubMed]

40. Furutani, Y.; Murakami, M.; Funaba, M. Differential responses to oxidative stress and calcium influx on expression of the transforming growth factor- $\beta$ family in myoblasts and myotubes. Cell Biochem. Funct. 2009, 27, 578-582. [CrossRef] [PubMed]

41. Ardite, E.; Barbera, J.A.; Roca, J.; Fernández-Checa, J.C. Glutathione depletion impairs myogenic differentiation of murine skeletal muscle C2C12 cells through sustained NF-kappaB activation. Am. J. Pathol. 2004, 165, 719-728. [CrossRef]

42. Piao, Y.J.; Seo, Y.H.; Hong, F.; Kim, J.H.; Kim, Y.J.; Kang, M.H.; Kim, B.S.; Jo, S.A.; Jo, I.; Jue, D.M.; et al. Nox 2 stimulates muscle differentiation via NF-kappaB/iNOS pathway. Free Radic. Biol. Med. 2005, 38, 989-1001. [CrossRef] [PubMed]

43. Mofarrahi, M.; Brandes, R.P.; Gorlach, A.; Hanze, J.; Terada, L.S.; Quinn, M.T.; Mayaki, D.; Petrof, B.; Hussain, S.N. Regulation of proliferation of skeletal muscle precursor cells by NADPH oxidase. Antioxid. Redox Signal. 2008, 10, 559-574. [CrossRef] [PubMed]

44. Ding, Y.; Choi, K.J.; Kim, J.H.; Han, X.; Piao, Y.; Jeong, J.H.; Choe, W.; Kang, I.; Ha, J.; Forman, H.J.; et al. Endogenous hydrogen peroxide regulates glutathione redox via nuclear factor erythroid 2-related factor 2 downstream of phosphatidylinositol 3-kinase during muscle differentiation. Am. J. Pathol. 2008, 172, 1529-1541. [CrossRef] [PubMed]

45. Rom, O.; Kaisari, S.; Aizenbud, D.; Reznick, A.Z. Identification of possible cigarette smoke constituents responsible for muscle catabolism. J. Muscle Res. Cell Motil. 2012, 33, 199-208. [CrossRef] [PubMed]

46. Rom, O.; Kaisari, S.; Aizenbud, D.; Reznick, AZ. The effects of acetaldehyde and acrolein on muscle catabolism in C2 myotubes. Free Radic. Biol. Med. 2013, 65, 190-200. [CrossRef] [PubMed]

47. Nakamura, M.; Tomitori, H.; Suzuki, T.; Sakamoto, A.; Terui, Y.; Saiki, R.; Dohmae, N.; Igarashi, K.; Kashiwagi, K. Inactivation of GAPDH as one mechanism of acrolein toxicity. Biochem. Biophys. Res. Commun. 2013, 430, 1265-1271. [CrossRef] [PubMed]

48. Hirose, T.; Saiki, R.; Uemura, T.; Suzuki, T.; Dohmae, N.; Ito, S.; Takahashi, H.; Ishii, I.; Toida, T.; Kashiwagi, K.; et al. Increase in acrolein-conjugated immunoglobulins in saliva from patients with primary Sjögren's syndrome. Clin. Chim. Acta 2015, 450, 184-189. [CrossRef] [PubMed]

49. Uemura, T.; Suzuki, T.; Saiki, R.; Dohmae, N.; Ito, S.; Takahashi, H.; Toida, T.; Kashiwagi, K.; Igarashi, K.1. Activation of MMP-9 activity by acrolein in saliva from patients with primary Sjögren's syndrome and its mechanism. Int. J. Biochem. Cell Biol. 2017, 88, 84-91. [CrossRef] [PubMed]

50. Uemura, T.; Takasaka, T.; Igarashi, K.; Ikegaya, H. Spermine oxidase promotes bile canalicular lumen formation through acrolein production. Sci. Rep. 2017, 7, 14841. [CrossRef] [PubMed]

51. Eisenberg, T.; Knauer, H.; Schauer, A.; Büttner, S.; Ruckenstuhl, C.; Carmona-Gutierrez, D.; Ring, J.; Schroeder, S.; Magnes, C.; Antonacci, L.; et al. Induction of autophagy by spermidine promotes longevity. Nat. Cell Biol. 2009, 11, 1305-1314. [CrossRef] [PubMed]

52. Minois, N. Molecular basis of the 'anti-aging' effect of spermidine and other natural polyamines-A Mini Review. Gerontology 2014, 60, 319-326. [CrossRef] [PubMed]

53. Abukhalaf, I.K.; Von Deutsch, D.A.; Wineski, L.E.; Silvestrov, N.A.; Abera, S.A.; Sahlu, S.W.; Potter, D.E. Effect of hindlimb suspension and clenbuterol treatment on polyamine levels in skeletal muscle. Pharmacology 2002, 65, 145-154. [CrossRef] [PubMed]

54. Levine, B.; Kroemer, G. Autophagy in the pathogenesis of disease. Cell 2008, 132, 27-42. [CrossRef] [PubMed]

55. Rogov, V.; Deotsch, V.; Johansen, T.; Kirkin, V. Interactions between autophagy receptors and ubiquitin-like proteins form the molecular basis for selective autophagy. Mol. Cell 2014, 53, 167-178. [CrossRef] [PubMed]

56. Chrisam, M.; Pirozzi, M.; Castagnaro, S.; Blaauw, B.; Polishchuck, R.; Cecconi, F.; Grumati, P.; Bonaldo, P. Reactivation of autophagy by spermidine ameliorates the myopathic defects of collage, I-null mice. Autophagy 2015, 11, 2142-2152. [CrossRef] [PubMed]

57. Sanchez, A.M.; Bernardi, H.P.G.; Candau, R.B. Autophagy is essential to support skeletal muscle plasticity in response to endurance exercise. Am. J. Physiol. Regul. Integr. Comp. Physiol. 2014, 307, 956-969. [CrossRef] [PubMed]

58. Szathmáry, I.; Selmeci, L.; Szobor, A.; Molnár, J. Altered polyamine levels in skeletal muscle of patients with myasthenia gravis. Clin. Neuropathol. 1994, 13, 181-184. [PubMed] 
59. Song, X.; Bao, M.; Li, D.; Li, Y.M. Advanced glycation in D-galactose induced mouse aging model. Mech. Ageing Dev. 1999, 108, 239-251. [CrossRef]

60. Du, Z.; Yang, Q.; Liu, L.; Li, S.; Zhao, J.; Hu, J.; Liu, C.; Qian, D.; Gao, C. NADPH oxidase 2-dependent oxidative stress, mitochondrial damage and apoptosis in the ventral cochlear nucleus of D-galactose-induced aging rats. Neuroscience 2015, 286, 281-292. [CrossRef] [PubMed]

61. Greer, E.L.; Oskoui, P.R.; Banko, M.R.; Maniar, J.M.; Gygi, M.P.; Gygi, S.P.; Brunet, A. The energy sensor AMP-activated protein kinase directly regulates the mammalian FOXO3 transcription factor. J. Biol. Chem. 2007, 282, 30107-30119. [CrossRef] [PubMed]

62. Tirupathi Pichiah, P.B.; Suriyakalaa, U.; Kamalakkannan, S.; Kokilavani, P.; Kalaiselvi, S.; SankarGanesh, D.; Gowri, J.; Archunan, G.; Cha, Y.S.; Achiraman, S. Spermidine may decrease ER stress in pancreatic beta cells and may reduce apoptosis via activating AMPK dependent autophagy pathway. Med. Hypotheses 2011, 77, 677-679. [CrossRef] [PubMed]

63. Bonaldo, P.; Braghetta, P.; Zanetti, M.; Piccolo, S.; Volpin, D.; Bressan, G.M. Collagen VI deficiency induces early onset myopathy in the mouse: An animal model for Bethlem myopathy. Hum. Mol. Genet. 1998, 7 , 2135-2140. [CrossRef] [PubMed]

64. Grumati, P.; Coletto, L.; Sabatelli, P.; Cescon, M.; Angelin, A.; Bertaggia, E.; Blaauw, B.; Urciuolo, A.; Tiepolo, T.; Merlini, L.; et al. Autophagy is defective in collagen VI muscular dystrophies, and its reactivation rescues myofiber degeneration. Nat. Med. 2010, 16, 1313-1320. [CrossRef] [PubMed]

65. Mammucari, C.; Milan, G.; Romanello, V.; Masiero, E.; Rudolf, R.; Del Piccolo, P.; Burden, S.J.; Di Lisi, R.; Sandri, C.; Zhao, J.; et al. FoxO3 controls autophagy in skeletal muscle in vivo. Cell Metab. 2007, 6, 458-471. [CrossRef] [PubMed]

66. Bernardi, P.; Bonaldo, P. Dysfunction of mitochondria and sarcoplasmic reticulum in the pathogenesis of collagen VI muscular dystrophies. Ann. N. Y. Acad. Sci. 2008, 1147, 303-311. [CrossRef] [PubMed]

67. Bertaggia, E.; Coletto, L.; Sandri, M. Posttranslational modifications control FoxO3 activity during denervation. AJP Cell Physiol. 2012, 302, 587-596. [CrossRef] [PubMed]

68. Pietrocola, F.; Lachkar, S.; Enot, D.P.; Niso-Santano, M.; Bravo-San Pedro, J.M.; Sica, V.; Izzo, V.; Maiuri, M.C.; Madeo, F.; Marino, G.; et al. Spermidine induces autophagy by inhibiting the acetyltransferase EP300. Cell Death Differ. 2014, 22, 509-516. [CrossRef] [PubMed]

69. Virgili, M.; Crochemore, C.; Peña-Altamira, E.; Contestabile, A. Regional and temporal alterations of ODC/polyamine system during ALS-like neurodegenerative motor syndrome in G93A transgenic mice. Neurochem. Int. 2006, 48, 201-207. [CrossRef] [PubMed]

70. Sirrieh, R.E.; MacLean, D.M.; Jayaraman, V. Subtype-dependent N-methyl-D-aspartate receptor amino-terminal domain conformations and modulation by spermine. J. Biol. Chem. 2015, 290, 12812-12820. [CrossRef] [PubMed]

71. Patin, F.; Corcia, P.; Vourc'h, P.; Nadal-Desbarats, L.; Baranek, T.; Goossens, J.F.; Bruno, C. Omics to Explore Amyotrophic Lateral Sclerosis Evolution: The Central Role of Arginine and Proline Metabolism. Mol. Neurobiol. 2017, 54, 5361-5374. [CrossRef] [PubMed]

72. Ponnusamy, S.; Sullivan, R.D.; You, D.; Zafar, N.; He Yang, C.; Thiyagarajan, T.; Johnson, D.L.; Barrett, M.L.; Koehler, N.J.; Star, M.; et al. Androgen receptor agonists increase lean mass, improve cardiopulmonary functions and extend survival in preclinical models of Duchenne muscular dystrophy. Hum. Mol. Genet. 2017, 26, 2526-2540. [CrossRef] [PubMed]

73. Cozzoli, A.; Capogrosso, R.F.; Sblendorio, V.T.; Dinardo, M.M.; Jagerschmidt, C.; Namour, F.; Camerino, G.M.; De Luca, A. GLPG0492, a novel selective androgen receptor modulator, improves muscle performance in the exercised-mdx mouse model of muscular dystrophy. Pharmacol. Res. 2013, 72, 9-24. [CrossRef] [PubMed]

74. Schwenk, F.; Baron, U.; Rajewsky, K. A cre-transgenic mouse strain for the ubiquitous deletion of loxP-flanked gene segments including deletion in germ cells. Nucleic Acids Res. 1995, 23, 5080-5081. [CrossRef] [PubMed]

75. Ceci, R.; Duranti, G.; Leonetti, A.; Pietropaoli, S.; Spinozzi, F.; Marcocci, L.; Amendola, R.; Cecconi, F.; Sabatini, S.; Mariottini, P.; et al. Adaptive responses of heart and skeletal muscle to spermine oxidase overexpression: Evaluation of a new transgenic mouse model. Free Radic. Biol. Med. 2017, 103, $216-225$. [CrossRef] [PubMed]

76. Ji, L.L. Exercise at old age: Does it increase or alleviate oxidative stress? Ann. N. Y. Acad. Sci. 2001, 928, 236-247. [CrossRef] [PubMed] 
77. Lang, F.; Aravamudhan, S.; Nolte, H.; Tuerk, C.; Hölper, S.; Müller, S.; Krüger, M. Dynamic changes in the skeletal muscle proteome during denervation-induced atrophy. Dis. Models Mech. 2017, 10, 881-896. [CrossRef] [PubMed]

78. Cruz-Jentoft, A.J.; Landi, F.; Schneider, S.M.; Zuniga, C.; Arai, H.; Boirie, Y.; Chen, LK.; Fielding, R.A.; Martin, F.C.; Michel, J.P.; et al. Prevalence of and interventions for sarcopenia in ageing adults: A systematic review. Report of the International Sarcopenia Initiative (EWGSOP and IWGS). Age Ageing 2014, 43, 748-759. [CrossRef] [PubMed]

79. Cerrada-Gimenez, M.; Pietilä, M.; Loimas, S.; Pirinen, E.; Hyvönen, M.T.; Keinänen, T.A.; Alhonen, L. Continuous oxidative stress due to activation of polyamine catabolism accelerates aging and protects against hepatotoxic insults. Transgenic Res. 2011, 20, 387-396. [CrossRef] [PubMed]

80. Tancini, B.; Urbanelli, L.; Magini, A.; Polchi, A.; Emiliani, C. Extending lifespan through autophagy stimulation: A future perspective. JGG 2017, 65, 110-123.

2018 by the authors. Licensee MDPI, Basel, Switzerland. This article is an open access article distributed under the terms and conditions of the Creative Commons Attribution (CC BY) license (http:/ / creativecommons.org/licenses/by/4.0/). 